\title{
EFEITO DOS DIÓXIDOS DE ENXOFRE E DE NITROGÊNIO NO DESEMPENHO DE UMA CÉLULA A COMBUSTÍVEL DE MEMBRANA DE INTERCÂMBIO DE PRÓTONS
}

\author{
Thiago Lopes e Ernesto R. Gonzalez* \\ Instituto de Química de São Carlos, Universidade de São Paulo, CP 780, 13560-970 São Carlos - SP, Brasil
}

Recebido em 13/3/07; aceito em 6/9/07; publicado na web em 26/2/08

\begin{abstract}
EFFECT OF SULFUR AND NITROGEN DIOXIDES ON THE PERFORMANCE OF A PROTON EXCHANGE MEMBRANE FUEL CELL. There is presently much interest in the clean and efficient generation of energy by proton exchange membrane fuel cells (PEMFC), using hydrogen as fuel. The generation of hydrogen by the reforming of other fuels, anaerobic fermentation of residual waters and other methods, often produce contaminants that affect the performance of the cell. In this work, the effect of gaseous $\mathrm{SO}_{2}$ and $\mathrm{NO}_{2}$ on the performance of a $\mathrm{H}_{2} / \mathrm{O}_{2}$ single PEMFC is studied. The results show that $\mathrm{SO}_{2}$ decreases irreversibly the performance of the cell under operating conditions, while $\mathrm{NO}_{2}$ has a milder effect that allows the recovery of the system.
\end{abstract}

Keywords: fuel cells; nitrogen dioxide; sulfur dioxide.

\section{INTRODUÇÃO}

A sociedade moderna busca formas de geração de energia mais eficientes, silenciosas, versáteis e de baixo impacto ambiental. Neste contexto as células a combustível surgem como uma potencial solução, sendo vislumbradas como a fonte de energia do futuro. São silenciosas, mais eficientes que os sistemas de geração de energia atuais e produzem o que os ecologistas chamam de energia limpa. As células a combustível são sistemas eletroquímicos conversores de energia química, de uma gama de combustíveis, diretamente em energia elétrica. São basicamente compostas por dois eletrodos, o ânodo onde ocorre a reação de oxidação do combustível, o cátodo onde ocorre a reação de redução do oxigênio e entre eles um eletrólito para completar o circuito. Dentre os diferentes tipos ${ }^{1}$ de células a combustível, as de membrana de intercâmbio de prótons ("Proton Exchange Membrane Fuel Cell, PEMFC") são atualmente vislumbradas para aplicações estacionárias, veiculares e portáteis.

As células a combustível apresentam uma eficiência na conversão de energia química em elétrica que pode chegar a 50\%. ${ }^{1}$ Já as máquinas térmicas não podem ultrapassar os $40 \%$ impostos pelo ciclo de Carnot. No entanto, na prática a eficiência deste tipo de sistema é bem inferior. Por exemplo, atualmente os motores de combustão interna a gasolina não ultrapassam os $20 \%$. Dentre os combustíveis utilizados nas PEMFC podemos citar os álcoois e o hidrogênio, sendo este último o que gera a maior densidade de potência na célula.

O hidrogênio atualmente é visto como o combustível do futuro. As principais vantagens são, poder ser obtido de fontes renováveis, apresentar uma densidade energética mássica superior a muitos outros combustíveis, não ser tóxico e poder ser produzido no local de consumo, pela reforma de uma grande variedade de compostos que incluem os combustíveis fósseis e os renováveis. Assim, alguns países como Japão e USA já assumiram em suas políticas de desenvolvimento que, no futuro, o hidrogênio será seu principal vetor energético, e com isso fazem grandes investimentos em toda a cadeia do hidrogênio, ou seja, produção, armazenamento, distribuição e aplicação.

A produção de hidrogênio pode ser feita por diferentes processos, partindo de várias fontes diferentes. Algumas formas que se

*e-mail: ernesto@iqsc.usp.br destacam são, a eletrólise da água, os processos termoquímicos, como a reforma de hidrocarbonetos, e a fermentação biológica. As fontes são as mais variadas, água, álcoois, hidrocarbonetos, biomassa, águas residuais, entre outras. A reforma de hidrocarbonetos é estudada para ser acoplada às células a combustível, num processo de produção de hidrogênio "on board". No entanto, além do $\mathrm{H}_{2}$, outros compostos como $\mathrm{CO}, \mathrm{H}_{2} \mathrm{~S}$ e $\mathrm{NH}_{3}$ estão presentes no gás rico em hidrogênio gerado em processos termoquímicos. Estes gases, no contexto das células a combustível, são classificados como contaminadores, pois quando presentes no gás de alimentação causam perdas de desempenho nas células ${ }^{1}$. Por considerações ambientais, atualmente a produção biológica de hidrogênio vem ganhando bastante interesse na comunidade científica. ${ }^{2-4}$ Este tipo de produção de hidrogênio tem a vantagem de não produzir metano. No entanto, algumas formas de produção biológica de hidrogênio também produzem alguns contaminadores, como $\mathrm{H}_{2} \mathrm{~S}, \mathrm{NO}_{2}$ e $\mathrm{SO}_{2}$, no caso de produção via fermentação anaeróbica de águas residuais.

$\mathrm{O}$ armazenamento de hidrogênio pode ser realizado de diferentes formas, com tanques criogênicos de alta pressão ou utilizandose de avançados materiais nos estados líquido e sólido, os quais apresentam a propriedade de absorver reversivelmente $\mathrm{H}_{2}$. O hidrogênio pode ser transportado do local de produção ao local de uso, através de gasodutos, caminhões tanque ou cilindros de alta pressão. A relativa baixa densidade volumétrica de energia, o difícil armazenamento, o transporte e a entrega final ao local de uso ainda elevam os custos da cadeia do hidrogênio, acarretando dificuldades na utilização do mesmo como vetor energético.

Dentre as fontes de hidrogênio, uma bastante importante para o ecossistema terrestre são as águas residuais, que são o esgoto líquido gerado por residências, indústrias etc. Estas águas que teoricamente seriam um descarte da sociedade tornam-se uma fonte de energia para a mesma. Neste caso o hidrogênio é produzido por bactérias, via fermentação anaeróbica, que além do hidrogênio geram outros gases como o $\mathrm{H}_{2} \mathrm{~S}$. Uma das composições do gás rico em hidrogênio produzido a partir de águas residuais é $45 \% \mathrm{H}_{2}, 20 \%$ $\mathrm{CO}_{2}, 35 \%$ ar $\left(\mathrm{NO}_{2}, \mathrm{SO}_{2}, \ldots\right)$ e $\mathrm{H}_{2} \mathrm{~S}(0,5$ e $5 \mathrm{ppm})$. Gases como $\mathrm{NO}_{2} \mathrm{e}$ $\mathrm{SO}_{2}$ podem ser introduzidos na célula através do ar presente no gás produzido pelas bactérias, e a concentração depende do ambiente onde a fermentação anaeróbica transcorre e da quantidade de ar presente no gás produzido. 
Nos eletrodos das células a combustível de baixa temperatura, utilizam-se catalisadores para que as reações decorram em potenciais úteis para a geração de trabalho elétrico. O principal catalisador é a platina, a qual é bastante sensível a compostos sulfurados, e levemente aos nitrogenados, os quais podem estar presentes como impurezas no gás rico em hidrogênio produzido via diferentes processos. Neste sentido, o estudo do comportamento de uma célula a combustível alimentada com hidrogênio contaminado com esses compostos é bastante importante. No sistema de tratamento de águas residuais, tem-se a bomba dosadora que alimenta os reatores de tratamento, a qual deve ser alimentada com energia elétrica que poderia ser fornecida por uma célula a combustível. O hidrogênio obtido da fermentação anaeróbica da própria água residual alimentaria a célula, tendo-se, portanto, um sistema autônomo. No entanto, para a viabilização deste sistema bastante importante para o ecossistema terrestre, é necessário compreender os efeitos que as impurezas presentes no hidrogênio produzido por bactérias alimentadas com águas residuais causam nas células a combustível.

Diversos estudos já foram realizados sobre o efeito do uso de hidrogênio contaminado nas células a combustível. Entretanto, os resultados dependem muito do sistema pesquisado e das condições de operação, de modo que resultados encontrados na literatura são de caráter geral e não são diretamente aplicáveis em qualquer sistema.

O Brasil apresenta severos problemas de poluição, entre outros, a contaminação de águas provocada por resíduos industriais ou por grandes urbanizações não planejadas. Isto tem motivado alguns grupos de pesquisa, como o Laboratório de Processos Biológicos - EESC/USP, a estudar e implementar a geração de combustíveis (metano, hidrogênio) através da fermentação anaeróbica de águas residuais. Haveria portanto um grande interesse no aproveitamento desse hidrogênio em células a combustível, mas será necessário considerar os efeitos de se trabalhar com hidrogênio contaminado. O Grupo de Eletroquímica de São Carlos, assim como outros grupos de pesquisa e algumas microempresas, vêm desenvolvendo células a combustível que poderiam ser consideradas para o aproveitamento do hidrogênio gerado de águas residuais, de processos de reforma etc. Entretanto, será necessário realizar um estudo detalhado do efeito de contaminadores para contornar os problemas criados pela sua presença. Neste trabalho, é feito um estudo dos efeitos de se alimentar uma célula a combustível de membrana de troca de prótons com hidrogênio contaminado com $\mathrm{SO}_{2}$ ou com $\mathrm{NO}_{2}$, sendo que este trabalho pode ser considerado o início desse tipo de estudos no país.

\section{PARTE EXPERIMENTAL}

Para os estudos utilizou-se uma célula a combustível unitária do tipo PEMFC ("Proton Exchange Membrane Fuel Cell") desenvolvida no laboratório de eletroquímica do Instituto de Química de São Carlos, com área de eletrodo de $4,6 \mathrm{~cm}^{2}$. O conjunto membrana/eletrodos ("membrane/electrode assembly, MEA") foi confeccionado como descrito por Paganin et al.. A camada catalítica é composta de catalisador, Pt/C $20 \%$ em massa da E-TEK, a uma carga de

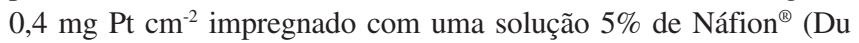
Pont). Separando os eletrodos e completando o circuito elétrico, usou-se uma membrana de Nafion ${ }^{\circledR} 115$ (Du Pont). Para se medir os potenciais do ânodo ou cátodo isoladamente, utilizou-se como referência um eletrodo reversível de hidrogênio ligado iônicamente à membrana polimérica (Nafion ${ }^{\circledR} 115$ ) por uma solução $0,5 \mathrm{~mol} \mathrm{~L}^{-1}$ de $\mathrm{H}_{2} \mathrm{SO}_{4}$. Como gases reagentes utilizaram-se, no cátodo oxigênio $(99,99 \%)$ e no ânodo hidrogênio $(99,999 \%)$ ou um gás rico em hidrogênio contendo $\mathrm{H}_{2}$ (50\% vol.) e $\mathrm{N}_{2}(99,99 \%$ ) (50\% vol.) com 20 ppm de $\mathrm{SO}_{2}(99,5 \%)$ ou 20 ppm de $\mathrm{NO}_{2}(99,5 \%)$, sempre à pressão atmosférica, sendo os gases fornecidos pela empresa AGA. Para se obter o gás de alimentação da célula, utilizaram-se fluxímetros mássicos. Para realizar o levantamento das curvas de desempenho (potencial-corrente) utilizou-se uma fonte de corrente modelo TCA XR1A (Tectrol). Os experimentos de voltametria cíclica foram realizados com um potenciostato 1285 A Solartron conectado a um computador pessoal utilizando o software CorrWare para Windows. Nestes experimentos o cátodo da célula foi purgado com hidrogênio e o ânodo com nitrogênio. Assim, o cátodo da célula atua como referência e contra-eletrodo, e o ânodo como eletrodo de trabalho, sendo a rampa de potenciais aplicada ao eletrodo de trabalho entre 0,075 e $1,2 \mathrm{~V}$ com velocidade de varredura de $10 \mathrm{mV} \mathrm{s}^{-1}$.

\section{RESULTADOS E DISCUSSÃO}

\section{Contaminação por $\mathrm{SO}_{2}$}

A Figura 1 apresenta o desempenho da célula a combustível do tipo PEM alimentada com gás rico em hidrogênio sem e com 10 ppm de $\mathrm{SO}_{2}$. Como se pode perceber, a perda de desempenho causada por pequenas quantidades deste contaminador é bastante drástica e após a contaminação a passagem de $\mathrm{H}_{2}$ puro não promove a recuperação do desempenho. Isto é devido a que ao se alterar o gás para hidrogênio puro o sobrepotencial diminui (Figura 6) e as espécies que contêm enxofre são reduzidas. Na Figura 2, nota-se que em aproximadamente $3 \mathrm{~h}$ de alimentação da célula com este gás contaminado, e sob uma corrente fixa de $0,5 \mathrm{~A} \mathrm{~cm}^{-2}$, o potencial da célula cai para valores que tornam a operação inviável.

Para o cátodo, Mohtadi et al. ${ }^{6}$ e Moore et al. ${ }^{7}$ também verificaram que o $\mathrm{SO}_{2}$ é um forte contaminador. Mohtadi et al. ${ }^{6}$ encontraram que após aproximadamente $50 \mathrm{~h}$ de exposição da célula a apenas 2,5 ppm de $\mathrm{SO}_{2}$, com o potencial da célula fixo em 0,68-0,70 V, a perda em corrente é de $50 \%$, e que para 5 ppm pouco mais de 20 $\mathrm{h}$ de exposição levam a uma perda de corrente de $80 \%$. Os autores ainda sugerem que a perda de desempenho da célula se dá pela desativação dos sítios ativos da platina, o que ocorre devido à forte adsorção de compostos contendo enxofre sobre a platina, processo ilustrado pelas reações 1 e 2 :

$$
\begin{aligned}
& \mathrm{SO}_{2}+\mathrm{H}_{2}+2 \mathrm{e}^{-} \stackrel{\mathrm{Pt}}{\rightarrow} \mathrm{Pt}-\mathrm{SO}+\mathrm{H}_{2} \mathrm{O} \\
& \mathrm{Pt}-\mathrm{SO}+2 \mathrm{H}^{+}+2 \mathrm{e}^{-} \stackrel{\mathrm{Pt}}{\rightarrow} \mathrm{Pt}-\mathrm{S}+\mathrm{H}_{2} \mathrm{O}
\end{aligned}
$$

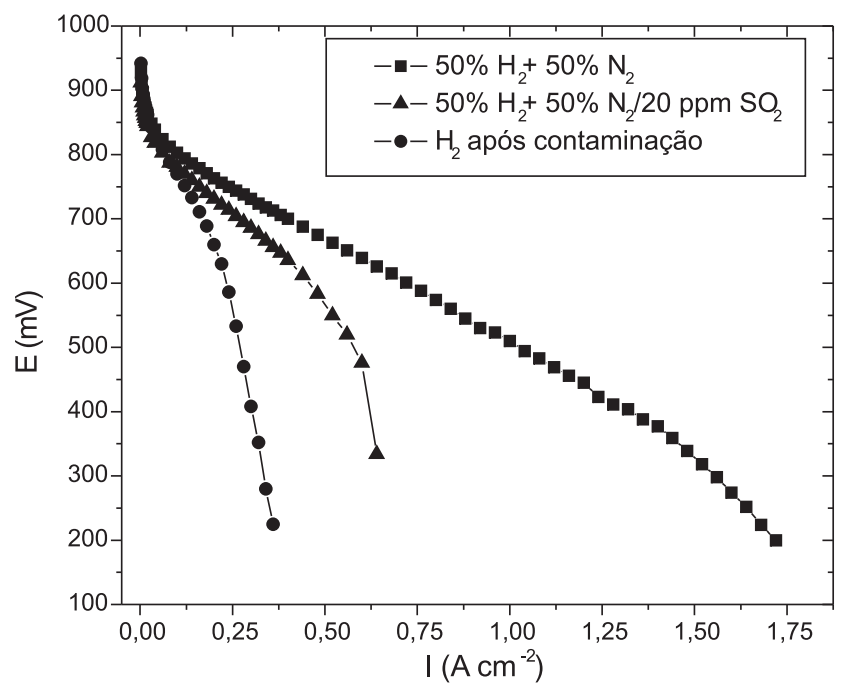

Figura 1. Comportamento de uma PEMFC com 10 ppm de $\mathrm{SO}_{2}$ no gás combustivel 


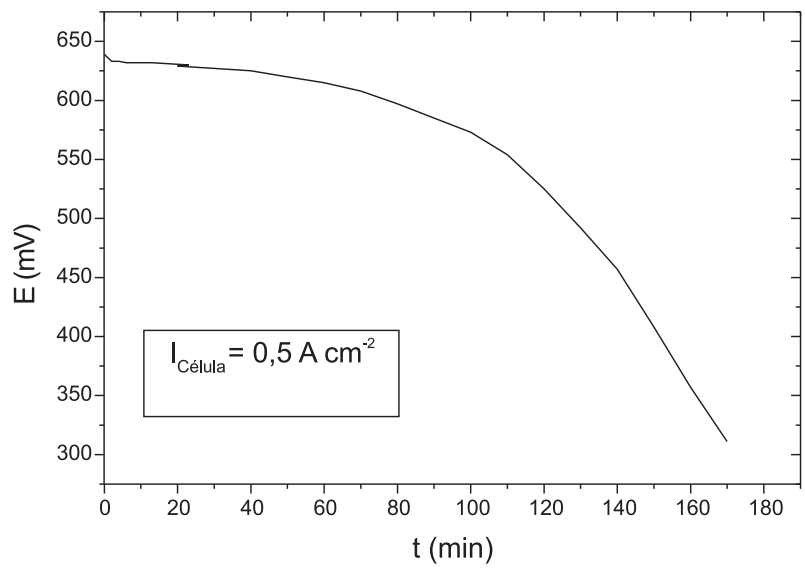

Figura 2. Queda de desempenho de uma PEMFC com 10 ppm de $\mathrm{SO}_{2}$ no gás combustível, em função do tempo

Para o ânodo, Uribe et al. ${ }^{8}$ verificaram que uma célula a combustível do tipo PEM alimentada com $\mathrm{H}_{2}$ contaminado com 1 ppm de $\mathrm{H}_{2} \mathrm{~S}$, tem seu desempenho drasticamente reduzido e que, quando o potencial da célula é fixado em $0,5 \mathrm{~V}$, a perda das condições de operação da célula se dá após aproximadamente $5 \mathrm{~h}$ de exposição a esta mistura de gases.

Um dos métodos para limpar superfícies eletródicas contaminadas com adsorbatos é submeter a superfície a varreduras cíclicas de potencial. A Figura 3 mostra a completa recuperação do desempenho da célula PEM cujo ânodo foi exposto a um gás de alimentação contendo $10 \mathrm{ppm}$ de $\mathrm{SO}_{2}$. Isto foi verificado após efetuar-se uma limpeza do eletrodo, submetendo-o a voltametrias cíclicas (VC) sob uma rampa de potenciais entre 0,075 e 1,4 V, com velocidade de varredura de $50 \mathrm{mv} \mathrm{s}^{-1}$. Este fato também foi verificado por Mohtadi et al. ${ }^{6}$ para a contaminação catódica por $\mathrm{SO}_{2}$.

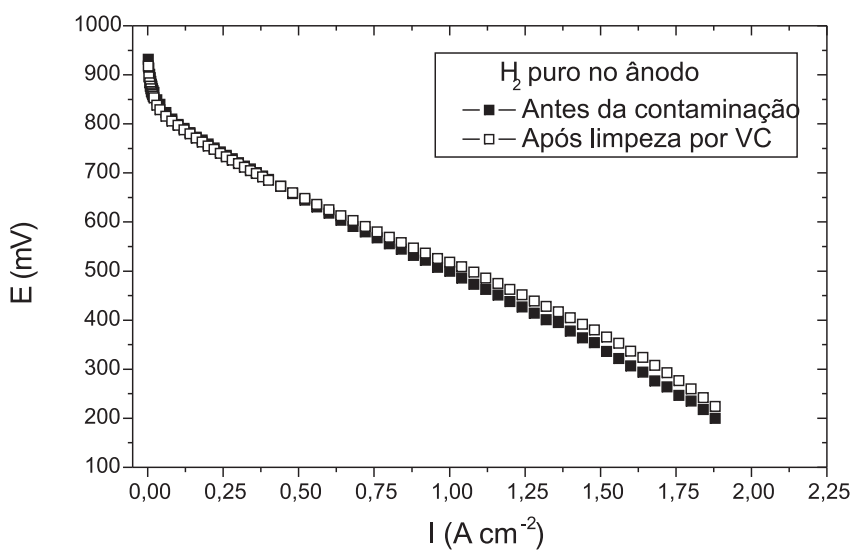

Figura 3. Comportamento de uma PEMFC com $\mathrm{H}_{2}$ puro antes da contaminação anódica por 10 ppm de $\mathrm{SO}_{2}$ e após limpeza do eletrodo por voltametria cíclica, a $50 \mathrm{mV} \mathrm{s}^{-1}$

Este comportamento é similar ao relatado na literatura ${ }^{8}$ no caso da contaminação por $\mathrm{H}_{2} \mathrm{~S}$, onde também se verificou que ao se efetuar uma limpeza do eletrodo, submetendo-o a varreduras de potencial (voltametria cíclica), o desempenho da célula é completamente recuperado.

Estes resultados indicam que tanto o $\mathrm{SO}_{2}$ quanto o $\mathrm{H}_{2} \mathrm{~S}$ envenenam a célula pelo mesmo processo, ou seja, através da forte adsorção de espécies contendo enxofre. Na literatura, Loucka, ${ }^{9}$ Contractor, ${ }^{10}$ Tarasevich et al. ${ }^{11}$ e Quijada et al. ${ }^{12}$ apresentaram estudos em solu- ção aquosa que mostram a forte adsorção de espécies sulfuradas sobre a platina. Quijada et al. ${ }^{12}$ relatam que em circuito aberto $\mathrm{SO}_{2}$ adsorve-se em um eletrodo de platina poli-orientada. Subsequientemente pode ser reduzido a um potencial de $0,06 \mathrm{~V}$, gerando com isso um eletrodo de platina modificado por enxofre, e sugere-se que este adsorbato seja enxofre elementar, visto que as características voltamétricas deste eletrodo modificado, em ausência de $\mathrm{SO}_{2}$, são as de enxofre adsorvido. Contractor et al. ${ }^{10}$ imergiram um eletrodo de platina lisa em uma solução contendo $\mathrm{H}_{2} \mathrm{~S}$, sob um potencial de 0,0 $\mathrm{V}$ por 15 min e observaram, efetuando uma voltametria de varredura linear em $80^{\circ} \mathrm{C}$, dois picos de oxidação, um em 0,97 e outro em 1,10 $\mathrm{V}$. Quando este processo foi realizado duas vezes, todo o adsorbato foi removido. Ainda nesse trabalho ${ }^{10}$ os autores encontraram resultados similares para $\mathrm{SO}_{2}$.

Todos estes resultados sugerem que ambos, $\mathrm{SO}_{2}$ e $\mathrm{H}_{2} \mathrm{~S}$, em contato com platina sob baixos potenciais, relativos aos potenciais de trabalho de um ânodo de uma célula a combustível, são reduzidos formando compostos de enxofre fortemente adsorvidos na superfície da platina. Isto bloqueia os sítios ativos da platina para a reação de oxidação de hidrogênio, explicando assim a elevada perda de desempenho da célula a combustível quando exposta a $10 \mathrm{ppm}$ de $\mathrm{SO}_{2}$ como contaminador do gás combustível. Câmara et al. ${ }^{13}$ mostraram que o envenenamento de uma PEMFC com 20 ppm de CO no gás combustível leva o potencial da célula a valores inviáveis em correntes acima de 1,0 A cm${ }^{-2}$. Já no envenenamento do ânodo da célula com apenas $10 \mathrm{ppm}$ de $\mathrm{SO}_{2}$, apresentado aqui, isto foi observado em correntes da ordem de $0,64 \mathrm{~A} \mathrm{~cm}^{-2}$. Pereira et al. ${ }^{14}$ mostraram um fato bastante conhecido para o caso de contaminação do ânodo da PEMFC por monóxido de carbono: após a interrupção do envenenamento do ânodo por $\mathrm{CO}$ e o retorno à alimentação com $\mathrm{H}_{2}$ puro, a célula se recupera e volta ao seu desempenho inicial. Procedimento semelhante foi adotado aqui para o envenenamento por $\mathrm{SO}_{2}$. No entanto, como mostrado na Figura 1, verificou-se que após a interrupção da contaminação por $\mathrm{SO}_{2}$, a célula apresenta um desempenho pior que o desempenho com $\mathrm{H}_{2} / \mathrm{N}_{2}+10$ ppm de $\mathrm{SO}_{2}$. Isto indica que o envenenamento do catalisador de platina é mais severo no caso do contaminador sulfurado, comparado ao envenenamento com $\mathrm{CO}$ ou $\mathrm{NO}_{2}$, devido à forte adsorção de espécies sulfuradas na superfície do catalisador. ${ }^{9-12}$ Estes resultados mostram o drástico e negativo efeito do $\mathrm{SO}_{2}$ quando presente no gás de alimentação da célula. No entanto, pouca atenção tem sido dada a este tipo de contaminador em comparação com o grande número de trabalhos relativos ao envenenamento com monóxido de carbono.

\section{Contaminação por $\mathrm{NO}_{2}$}

A Figura 4 apresenta os resultados de quando a célula é alimentada com o gás rico em hidrogênio contendo $10 \mathrm{ppm}$ de $\mathrm{NO}_{2}$. Durante o envenenamento, a célula apresenta uma pequena perda de desempenho, e sob as condições experimentais esta contaminação não é cumulativa, ou seja, a célula não sofre perdas de desempenho adicionais com a realização de consecutivas curvas de polarização. Após esta contaminação, o uso de $\mathrm{H}_{2}$ puro provoca uma recuperação parcial no desempenho da célula.

Submetendo-se o ânodo a uma varredura de potenciais (VC), após contaminação por gás rico em $\mathrm{H}_{2}$ contendo $10 \mathrm{ppm}$ de $\mathrm{NO}_{2}$, não se verificam picos de oxidação ou redução, como mostra a Figura 5. Mohtadi et al. ${ }^{7}$ também verificaram a ausência de picos de oxidação nos voltamogramas cíclicos do cátodo após contaminação por $5 \mathrm{ppm}$ de $\mathrm{NO}_{2}$. Estes resultados sugerem que a contaminação do eletrodo pelo $\mathrm{NO}_{2}$ não seja provocada por espécies fortemente adsorvidas na superfície do catalisador.

Vários trabalhos sobre os efeitos da contaminação iônica do 


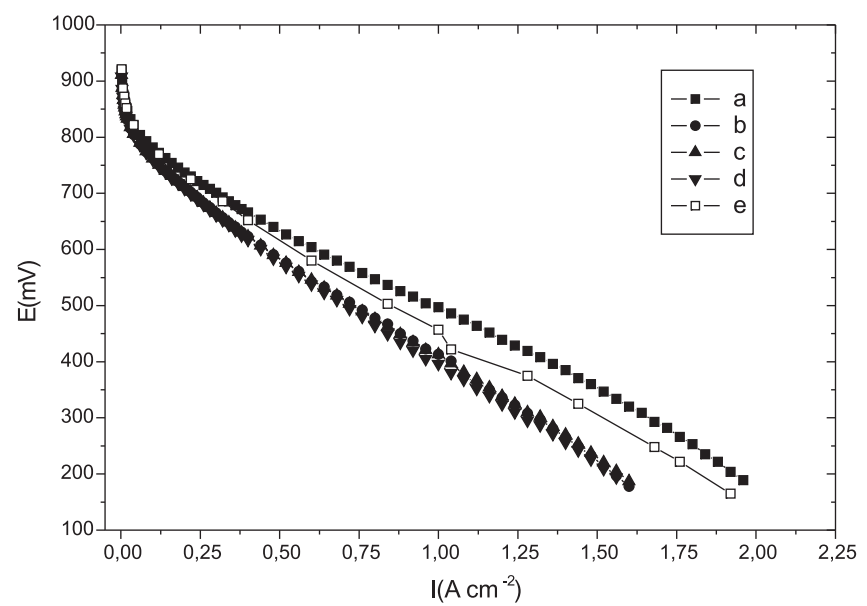

Figura 4. Comportamento de uma PEMFC sob contaminação anódica: $a=$ $\mathrm{H}_{2}+\mathrm{N}_{2}, \mathrm{~b}=\mathrm{H}_{2}+\mathrm{N}_{2}$ com 10 ppm NO após 1 h de contaminação, $c=\mathrm{H}_{2}+$ $\mathrm{N}_{2}$ com 10 ppm $\mathrm{NO}_{2}$ após $2 \mathrm{~h}$ de contaminação, $d=\mathrm{H}_{2}+\mathrm{N}_{2}$ com $10 \mathrm{ppm} \mathrm{NO}_{2}$ após 5,2 h de contaminação, $e=H_{2}+N_{2}$ após a contaminação

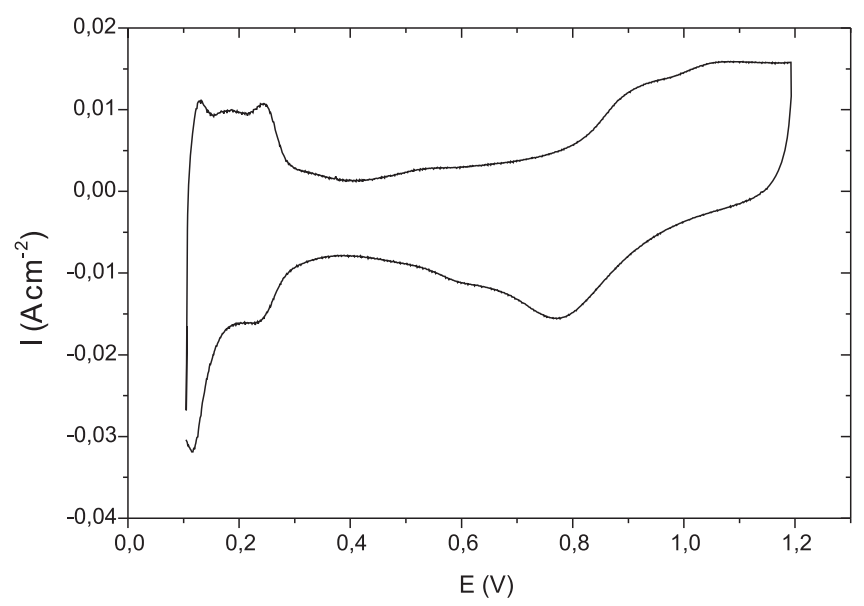

Figura 5. Voltametria cíclica do ânodo de uma célula PEM após contaminações por 10 ppm de $\mathrm{NO}_{2}$ no gás combustível. Velocidade de varredura $10 \mathrm{mV} \mathrm{s}^{-1}$

MEA, no desempenho de uma célula a combustível do tipo PEM, têm sido publicados por Wakizoe et al.,${ }^{15}$ Okada et al. ${ }^{16}$ e Uribe $e t$ al..${ }^{17} \mathrm{Em}$ seu trabalho, Uribe et al. ${ }^{17}$ mostram o efeito negativo do íon $\mathrm{NH}_{4}^{+}$sobre a condutividade iônica da membrana de Nafion ${ }^{\circledR}$, devido à permuta dos íons $\mathrm{H}^{+}$pelos $\mathrm{NH}_{4}^{+}$. Estes resultados e a reação $3^{18}$ sugerem algumas explicações dos efeitos do $\mathrm{NO}_{2}$ no desempenho da célula.

$\mathrm{NO}_{2}(\mathrm{~g})+8 \mathrm{H}^{+}+7 \mathrm{e}^{-} \rightarrow \mathrm{NH}_{4}^{+}+2 \mathrm{H}_{2} \mathrm{O} \mathrm{E}^{0}=0,897 \mathrm{~V}$

$\mathrm{E}^{0}=$ Potencial padrão da reação em meio ácido

No lado do ânodo pode haver a formação espontânea de íons nitrato, visto que anidridos de ácidos em presença de água tendem a formar seus respectivos ácidos, fato infelizmente verificado nos grandes centros urbanos com as chuvas ácidas. Estes íons podem alterar a condutividade iônica da camada catalítica, acarretando em problemas resistivos. Estes íons ainda podem levar a problemas na difusão do $\mathrm{H}_{2}$ até a superfície do catalisador, onde a reação de oxidação deste gás ocorre, acarretando em perdas de desempenho por transporte de massa, como mostra a Figura 6, onde as perdas de desempenho no ânodo, por resistividade e transporte de massa são ilustradas. Após a contaminação, a passagem de $\mathrm{H}_{2}$ puro prati- camente não gera melhoras no desempenho do ânodo. Isto pode ser explicado com base nos íons nitrato formados na camada catalítica a partir do $\mathrm{NO}_{2}$, que permanecem na mesma mesmo após a interrupção da contaminação. A curva "e" na Figura 6 mostra que os problemas de resistividade estão presentes na mesma magnitude e que uma pequena recuperação se dá na região controlada por transporte de massa.

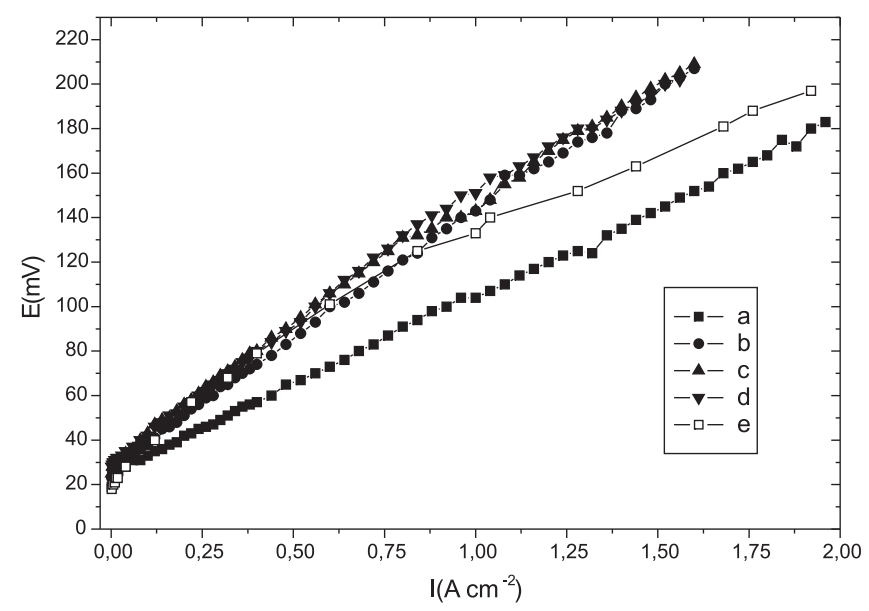

Figura 6. Potencial do anodo de uma PEMFC sob contaminação em função da densidade de corrente: $a=$ com $\mathrm{H}_{2}+\mathrm{N}_{2}, b=\mathrm{H}_{2}+\mathrm{N}_{2} \operatorname{com} 10$ ppm $\mathrm{NO}_{2}$ após $1 \mathrm{~h}$ de contaminação, $c=\mathrm{H}_{2}+\mathrm{N}_{2} \operatorname{com} 10$ ppm $\mathrm{NO}_{2}$ após $2 \mathrm{~h}$ de contaminação, $d=\mathrm{H}_{2}+\mathrm{N}_{2}$ com 10 ppm $\mathrm{NO}_{2}$ após 5,2 h de contaminação, $e$ $=\mathrm{H}_{2}+\mathrm{N}_{2}$ após a contaminação

A permeabilidade da membrana de Nafion ${ }^{\circledR}$ é um fenômeno observado em estudos de células a combustível do tipo PEM tendo como combustível os álcoois, como no trabalho de Song et al. ${ }^{19}$ Se o desempenho do cátodo da célula for analisado isoladamente, Figura 7, pode-se notar que há um cruzamento do gás contaminador do ânodo, pois perdas de desempenho são visivelmente observadas durante a contaminação (curvas b, c e d), sendo que após a contaminação (curva e) há uma quase total recuperação, mas perdas por transporte de massa ainda são verificadas. Este cruzamento pode levar, tendo em vista a reação 3, a problemas de difusão de água do cátodo para o ânodo, pois os íons amônio podem afetar o arraste eletro-osmótico. Isto acarretaria em uma diminuição da quantidade de água na membrana no lado do ânodo, o qual contribuiria para reduzir o desempenho da célula devido a perdas por resistividade na membrana.

Com base na reação 3 e no efeito negativo do íon $\mathrm{NH}_{4}^{+}$sobre a condutividade iônica da membrana de $\mathrm{Nafion}^{\circledR},{ }^{17}$ as perdas de desempenho por resistividade e por transporte de massa, mostrados na Figura 7, podem ser explicadas pela redução da condutividade iônica da membrana e, como para o ânodo, pela formação de filmes iônicos sobre a superfície do catalisador. Já a redução da resistividade, quando a célula opera com hidrogênio puro após as contaminações, é explicada pela recuperação da condutividade iônica da membrana por protonação da mesma, visto que prótons formados no ânodo cruzam a membrana no sentido do cátodo. Há trabalhos na literatura, como os de Fujiwara et al. ${ }^{20}$ e Liu et al. ${ }^{21}$ nos quais se considera depositar os metais catalíticos na própria membrana de Nafion ${ }^{\circledR}$ para produzir eletrodos para células a combustível. Nestes trabalhos primeiro faz-se uma troca iônica de $\mathrm{H}^{+}$ pelo cátion do metal catalítico desejado no interior da membrana e, em continuação, procede-se à redução deste metal. Para a regeneração da condutividade iônica da membrana faz-se uma protonação da mesma, imergindo-a em solução de ácido forte. As- 


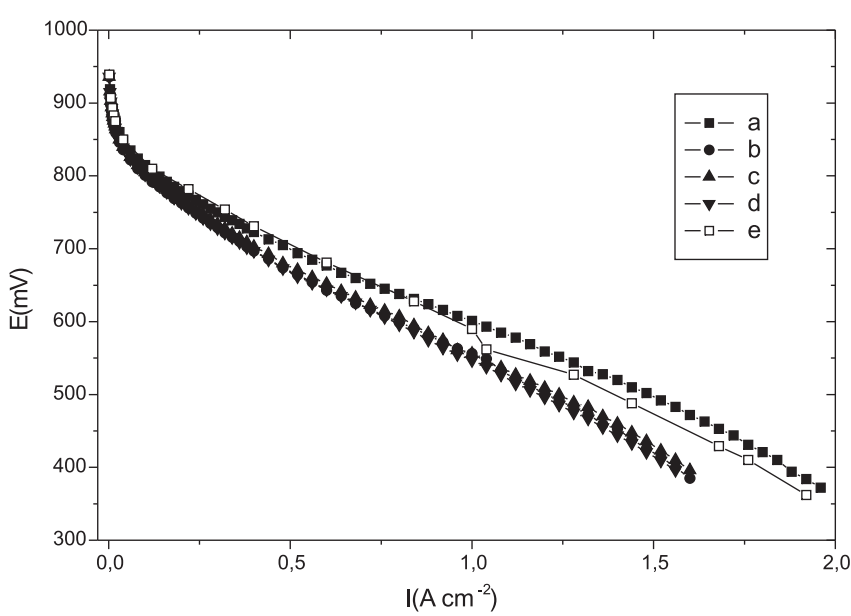

Figura 7. Potencial do cátodo de uma PEMFC sob contaminação anódica

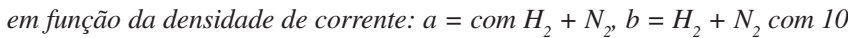
ppm $\mathrm{NO}_{2}$ após $1 \mathrm{~h}$ de contaminação, $c=\mathrm{H}_{2}+\mathrm{N}_{2} \operatorname{com} 10$ ppm $\mathrm{NO}_{2}$ após $2 \mathrm{~h}$ de contaminação, $d=\mathrm{H}_{2}+\mathrm{N}_{2}$ com $10 \mathrm{ppm} \mathrm{NO}$ após 5,2 h de contaminação, $e=H_{2}+N_{2}$ após a contaminação

sim, a protonação da membrana é um fato estudado e verificado. A recuperação do desempenho da célula sob prolongada operação em $\mathrm{H}_{2}$ puro pode levar a uma gradual recuperação no desempenho da mesma, podendo alcançar o nível inicial e deverá ser motivo de estudos futuros. A quantificação das concentrações de $\mathrm{SO}_{2}$ e $\mathrm{NO}_{2}$ toleradas pelas PEMFC é imprescindível para a aplicação prática deste tipo de sistemas.

\section{CONCLUSÕES}

Ao se alimentar o ânodo de uma PEMFC com gás rico em hidrogênio contendo $10 \mathrm{ppm}$ de $\mathrm{SO}_{2}$, grandes perdas de desempenho são observadas e ao se interromper a contaminação, e $\mathrm{H}_{2}$ puro ser novamente o combustível, não é verificada a recuperação no desempenho da célula. Isto é devido aos sítios ativos do catalisador estarem envenenados por compostos de enxofre fortemente adsorvidos. No entanto, após submeter-se o eletrodo a um processo de limpeza da superfície do catalisador, utilizando-se voltametria cíclica, tem-se uma total recuperação do desempenho da célula. Desta forma, uma fonte externa de energia poderia ser utilizada para, periodicamente, passar pulsos de corrente através dos eletrodos, e desta forma eliminar os compostos de enxofre adsorvidos no catalisador.

Quando a PEMFC é alimentada com gás rico em hidrogênio contendo $10 \mathrm{ppm}$ de $\mathrm{NO}_{2}$, existem perdas de desempenho, mas ao se realimentar a célula com $\mathrm{H}_{2}$ puro tem-se uma quase total recuperação do desempenho da mesma, sendo que isso ocorre devido à fraca adsorção do gás contaminador nos sítios ativos do catalisador e à recuperação da condutividade iônica da membrana.

\section{AGRADECIMENTOS}

À FAPESP e ao CNPq pela ajuda financeira. T. Lopes agradece a bolsa de doutorado outorgada pelo programa ProH2 do HCT/MME

\section{REFERÊNCIAS}

1. Fuel cell Handbook, $7^{\text {th }}$ ed., US Department of Energy: West Virginia, 2004, cap. 2.

2. Lee, K. S.; Lo, Y.-S.; Lo, Y.-C.; Lin, P.-J.; As, J.-S. C.; Biotechnol. Lett. 2003, 25, 133 .

3. Laurinavichene, T. V.; Fedorov, A. S.; Ghirardi, M. L.; Seibert, M.; Tsygankov, A. A.; Int. J. Hydrogen Energy 2006, 31, 659.

4. Tsygankov, A. A.; Kosourov, S. N.; Tolstygina, I. V.; Ghirardi, M. L.; Seibert, M.; Int. J. Hydrogen Energy 2006, 31, 1574.

5. Paganin, V. A.; Ticianelli, E. A.; Gonzalez, E. R.; J. Appl. Electrochem. 1996, 26, 297.

6. Mohtadi, R.; Lee, W.-K.; van Zee, J. W.; J. Power Sources 2004, 138, 216.

7. Moore, J. M.; Adcock, P. L.; Lakeman, J. B.; Mepsted, G. O.; J. Power Sources 2000, 85, 254.

8. Uribe, F. A.; Zawodzinski Jr, A.; 200 ${ }^{\text {th }}$ Meeting of The Electrochemistry Society, San Antonio, Texas, USA, 2001.

9. Loucha, T.; J. Electroanal. Chem. and Interfacial Electrochemistry 1970, 31,319 .

10. Contractor, A. Q.; Hira, L.; J. Electroanal. Chem. 1979, 96, 175.

11. Tarasevich, M. R.; Andreev, V. N.; Kazarinov, V. E.; Levina, O. A.; Radyushkina, K. A.; Elektrokhimiya 1982, 18, 1569.

12. Quijada, C.; Vázquez, J. L.; Aldaz, A.; J. Electroanal. Chem. 1996, 414, 229 .

13. Camara, G. A.; Ticianelli, E. A.; Mukerjee, S.; Lee, S. J.; McBreen, J.; J. Electrochem. Soc. 2002, 149, A748.

14. Pereira, L. G. S.; dos Santos, F. R.; Pereira, M. E.; Paganin, V. A.; Ticianelli, E. A.; Electrochim. Acta 2006, 51, 4061.

15. Wakizoe, M.; NEDO Report Fy, NEDO, 1997.

16. Okada, T.; Moller-Holst, S.; Gorseth, O.; Kjelstrup, S.; J. Electroanal. Chem. 1998, 442, 137; Okada, T.; Ayato, Y.; Yuasa, M.; Sekine, L.; J. Phys. Chem. B 1999, 103, 3315 .

17. Uribe, F. A.; Gottesfeld, S.; Zawodzinski. Jr, T. A.; J. Electrochem. Soc. 2002, 149, A293.

18. Bard, A. J.; Parsons, R.; Jordan, J. Em Standard Potentials in Aqueous Solution; Bard, A. J.; Parsons, R.; Jordan, J., eds.; M. Dekker: New York, 1985, cap. 7

19. Song, S.; Zhou, W.; Liang, Z.; Cai, R.; Sun, G.; Xin, Q.; Stergiopoulos, V.; Tsiakaras, P.; Appl. Catal., B 2005, 55, 65.

20. Fujiwara, N.; Yasuda, K.; Ioroi, T.; Siroma, Z.; Miyazaki, Y.; Electrochim. Acta 2002, 47, 4079

21. Liu, R.; Her, W.-H.; Fedkiw, P.S.; J. Electrochem. Soc. 1992, 139, 15. 